\title{
The formation and morphology of ice stalactites observed under deforming lead ice
}

\author{
Donald K. Perovich, Jacqueline A. Richter-Menge \\ U.S. Army Cold Regions Research and Engineering Laboratory, Hanover, New Hampshire 03755, U.S.A.
}

JAMES H. MORISON

Applied Physics Laboratory, University of Washington, Sealte, Washington 98105, U.S.A.

\begin{abstract}
During the LeadEx main field experiment, held in April 1992 in the Alaskan Beaufort Sea, a number of large ice stalactites were observed growing under young lead ice. Formation of the stalactites was associated with rafting of the thin, highly saline ice. The rafting caused the brine to drain rapidly from the ice at a temperature well below the freezing point of the surrounding water, which in turn caused ice to form in a hollow cylinder around the brine plume. Within a $15 \mathrm{~h}$ period after the rafting event, the stalactites, which were located approximately $10 \mathrm{~m}$ apart in a line along the up-wind edge of a $150 \mathrm{~m}$ wide lead, had grown to a length of $2 \mathrm{~m}$. A detailed structural analysis of the upper part of one of these stalactites revealed that the interior channel, down which the brine flowed, was bounded by a zone of frazil ice that developed into a shell of columnar ice. The growth of the columnar ice was directed radially outward and the $c$ axes of these crystals were oriented perpendicular to their growth direction. Development of the stalactites illustrates the impact ice deformation can have on the process of brine rejection in freezing leads and potentially on the thermohaline structure of the upper ocean in the immediate vicinity of the lead.
\end{abstract}

\section{INTRODUCTION}

When sea ice grows, salts are rejected into the underlying water as a highly saline brine. Introduction of this brine causes an increase in both the salinity and density of the water and, consequently, the development of an unstable buoyancy flux. In the case of a freezing lead, the buoyancy flux is concentrated in a narrow band, intensifying the effects of this instability on the thermohaline structure of the upper ocean. Models developed to assess the oceanographic impact of the process of brine rejection in freezing leads have focused on the effects of lead width and the ice-water velocity difference (Kozo, 1983; Smith and Morison, 1993). The surface boundary condition at the ice water interface, which describes the input of brine, is typically represented as a salt flux right at the surface or as a distributed source which decreases exponentially from the surface, reaching $1 / e$ of its surface value $2 \mathrm{~m}$ below the ice water interface Morison and others, 1992). In both cases, the salt flux is assumed to be horizontally uniform, reflecting an assumption that the process of brine rejection from the ice does not vary across the lead.

While studying brine rejection from freezing leads during the LeadEx main field experiment, we came to realize that ice deformation could have an impact on the process of brine rejection both by affecting the rate of brine rejection and by localizing the input of brine to the ocean (LeadEx Group, 1993). The most dramatic illustration of this came serendipitously, when we had the opportunity to observe and recover a part of a $2 \mathrm{~m}$ long ice stalactite that formed under the lead ice after a rafting event.

Large under-ice stalactites have been observed on numerous occasions. In particular, stalactites as long as $6 \mathrm{~m}$ have been reported to have occurred in McMurdo Sound, Antarctica (Paige, 1970; Dayton and Martin, 1971). However, an association between their development and ice deformation has only tenuously been made in these previous accounts. For example, Dayton and Martin (1971) remarked on a case where the stalactites formed after dynamite was used to blow a hole in the ice cover.

Martin (1974) successfully grew under-ice stalactites in the laboratory and, based on that work, developed a detailed description of the mechanisms associated with their growth. Briefly, sea ice consists of pockets of brine trapped in a fresh-ice matrix (Weeks and Ackley, 1986). Influenced by a variety of desalination processes, this brine drains down through the ice and forms a system of tubes or brine channels. At the ice water interface, the brine in these channels enters the sea water. Under freezing conditions, the draining brine is colder and saltier than the sea water, both of which are at their salinity determined freezing points. The colder brine rapidly gains heat by freezing water around itself. If the flow of brine is sufficient and sustained, this process continues and a stalactite forms around the plume of 
draining brine. Since salts cannot be correspondingly conducted through the walls of the stalactite, the concentration of the brine near the inner wall of the stalactite increases above the liquidus curve. To reestablish equilibrium, ice along the interior wall melts, cooling and diluting the adjacent brine. The source of heat for the interior melting is provided by the growth of ice at the outer wall. As a result of this process, the stalactite also becomes thicker as it grows in length.

Since the growth of large under-ice stalactites marks the injection of a considerable amount of cold, dense brine into the water column, interest in the process of their formation extends beyond simple curiosity. For instance, Dayton and Martin (1971) first commented on their potential impact on upper ocean mixing. In this paper, we suggest that the formation of stalactites is an indication of the role deformation may play in the desalination process of the ice sheet and also speculate on potential oceanographic implications associated with their development. Our comments are based on field observations made while the stalactites were growing and on a detailed structural analysis of a part of one stalactite. The latter adds a new perspective on the formation and growth process, since no previous reports have included data on the crystal structure of these ice features. Physical-property data from the retrieved stalactite are used to provide estimates of the brine flux associated with the development of the stalactites, which are then compared to the rate of brine rejection from undeformed lead ice.

\section{OBSERVATIONS}

The LeadEx main experiment, held in April 1992 in the Alaskan Beaufort Sea, was an interdisciplinary program designed to study ocean-ice-atmosphere interactions at freezing leads, where there are large fluxes of heat from the ocean to the atmosphere and of salt from the ice to the ocean. A major scientific focus of this program was studying the input of salt to the upper ocean from brine rejected from the freezing lead ice. Salt fluxes were estimated from detailed CTD casts in the upper ocean and from time-series measurements of the salinity of the lead ice. As part of the oceanographic program, we operated an Autonomous Conductivity Temperature Vehicle (ACTV) to measure salinity and temperature under leads. A small remotely operated vehicle (ROV), equipped with a television camera and special manipulator claw, was used to observe ACTV operations and provide back-up recovery. In the course of these operations at the edge of a $1 \mathrm{~d}$ old, $150 \mathrm{~m}$ wide lead, we observed under-ice stalactites. After monitoring the stalactites over an $8 \mathrm{~h}$ period, we used the ROV manipulator arm to retrieve one of the stalactites for a detailed structural analysis.

\section{Formation and growth}

In the early afternoon of 11 April, we began scientific operations at the up-wind edge of a newly opened lead. By that evening, the lead ice was a few centimeters thick. ROV observations made on the night of 11 April showed numerous small stalactites under the lead ice. These stalactites were approximately $0.1 \mathrm{~m}$ in length and appeared to be distributed uniformly on the bottom of the lead ice.

Between 0400 and $0600 \mathrm{~h}$ on the morning of 12 April, extensive rafting occurred along the up-wind edge of the lead: $0.07 \mathrm{~m}$ thick young ice was pushed onto the adjacent $0.90 \mathrm{~m}$ thick first-year sea-ice sheet. When the event was over, the young ice covered the thicker ice over an area $3.5 \mathrm{~m}$ wide. The skeletal layer of this thin ice was sheared off during the rafting, reducing its thickness to $0.04 \mathrm{~m}$. During an ROV run about $8 \mathrm{~h}$ later $(1300 \mathrm{~h})$, we observed an array of large ice stalactites growing under the thin lead ice in a line parallel to the edge of the adjacent thick ice (Fig. 1). The line of stalactites was located about $1 \mathrm{~m}$ from the thick ice edge, at the junction of the tilted, rafted ice and the level, undeformed lead ice. The stalactites were spaced approximately 5-10 $\mathrm{m}$ apart along this line. Figure 2 is a schematic showing the geometry of the rafted ice and stalactites. At the time of this first observation, the stalactites were about $1 \mathrm{~m}$ long and $0.06 \mathrm{~m}$ in diameter, and consisted of large, flat, loosely connected ice crystals. They had little structural integrity and would disintegrate when touched by the ROV manipulator arm. This frailty is evidenced in Figure 1 by the almost transparent appearance of the stalactite in the foreground.

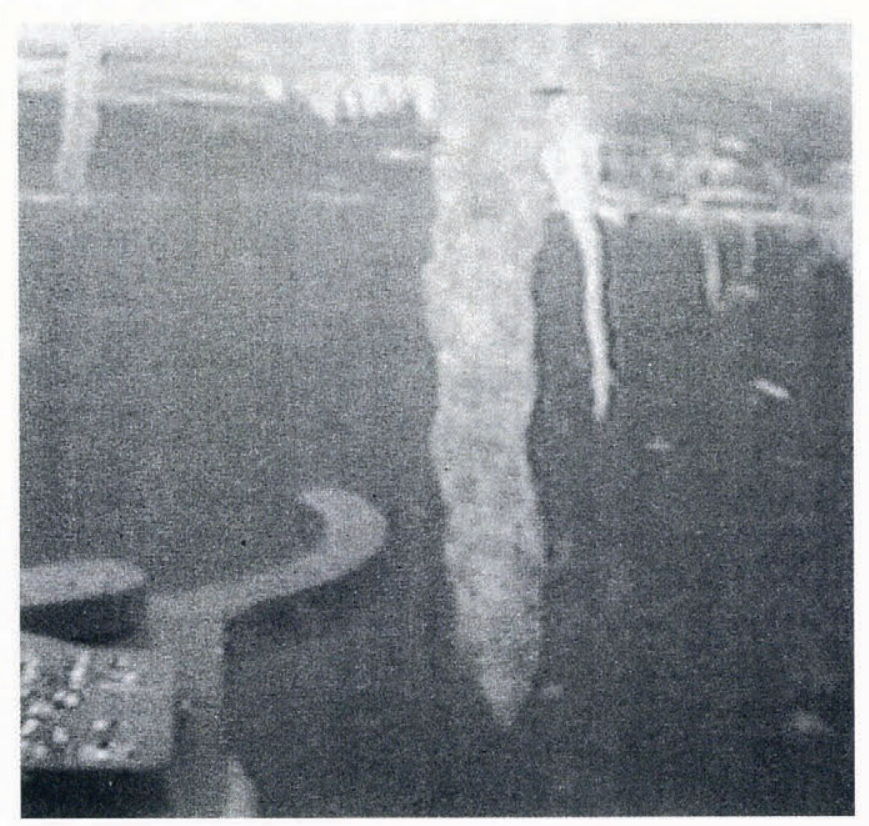

Fig. 1. Underwater photograph of ice stalactites laken at 1300 h on 12 April 1992, using the ROV video camera. The translucent appearance of the meter-long stalactite in the foreground is due to its being composed of a loose collection of large, platy crystals with high porosity. Note in the background how the long stalactites lie in a line.

$8 \mathrm{~h}$ later $(2100 \mathrm{~h})$ the stalactites had grown as large as $2 \mathrm{~m}$ in length and $0.1 \mathrm{~m}$ in diameter. They extended below the bottom of the thick ice and exhibited a slight curvature in the direction of the current. The ice in the upper meter of the stalactites had consolidated considerably, to the point where it was possible to use the ROV to 


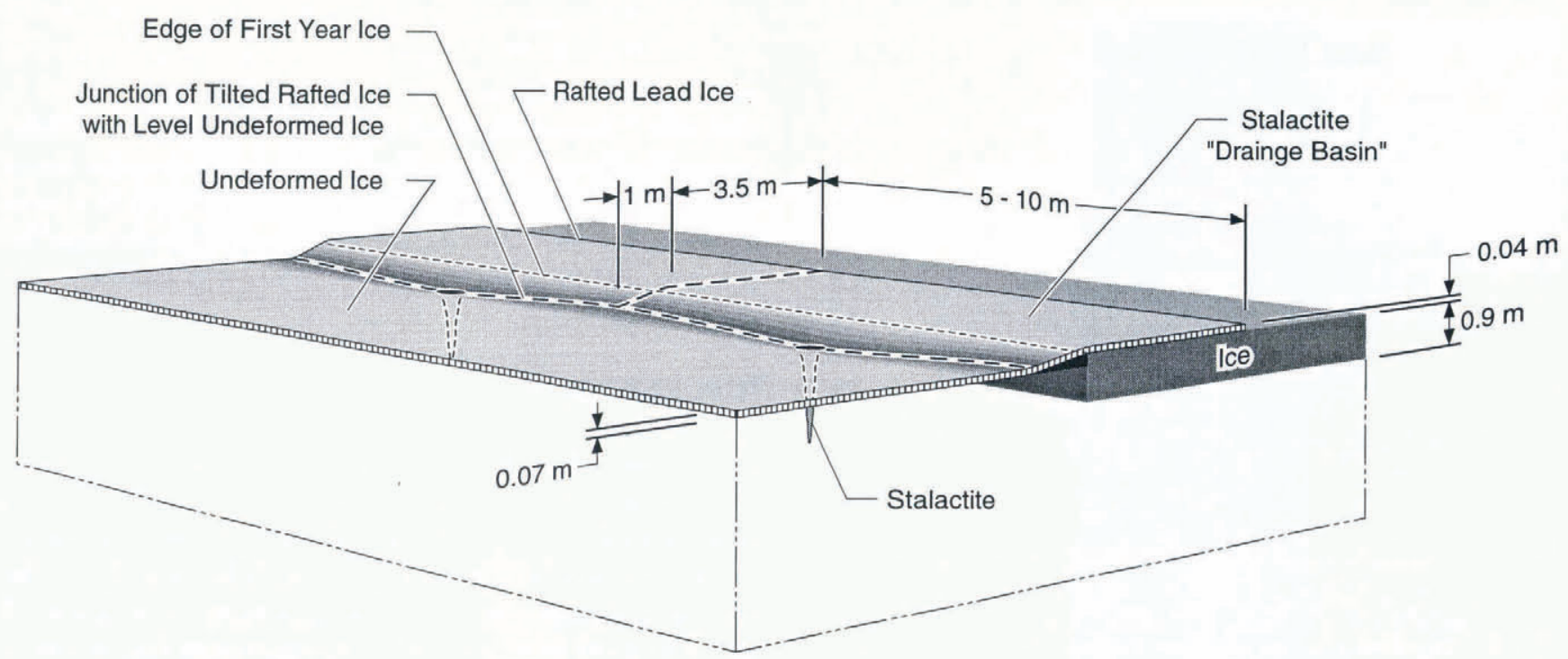

Fig. 2. Schematic illustrating the geometry of the rafted ice and stalactites.

retrieve a stalactite. During this retrieval, the still-fragile bottom part of the stalactite was lost but we were able to recover the top $0.75 \mathrm{~m}$.

As mentioned, the formation of an under-ice stalactite requires a plume of cold, dense brine (Martin, 1974). Measurements made on ice cores taken soon after the rafting event indicated that the temperature of the ice and, hence, the draining brine was approximately $-10^{\circ} \mathrm{C}$. This was well below the freezing point of the surrounding water, $-1.7^{\circ} \mathrm{C}$, resulting in the rapid growth of ice crystals around the brine plume. Also critical to the development of the larger stalactites is an adequate volume flux of brine. We believe that the recently rafted ice was the source of the requisite brine. The widely dispersed brine that was rejected from the thin, salty, undeformed lead ice is only adequate to create the smaller stalactites initially observed beneath the undeformed ice Dayton and Martin, 1971). Once this young ice was rafted, however, cooling of the ice and an increase in elevation resulted in a more rapid, and apparently more localized, drainage of brine.

\section{Morphology}

Since the upper part of the stalactite had consolidated, we were able to retrieve it, which provided a unique opportunity to investigate its morphology. A visual inspection in the field (Fig. 3) indicated that, while the outside wall of the stalactite had some small bumps and bends, the outside diameter $(0.1 \mathrm{~m})$ was remarkably constant along its length. One of the most immediately striking aspects of the stalactite was the tortuosity of the internal brine channel. It was not a simple cylindrical channel down the middle of the stalactite but rather a complex, twisting passageway that changed size, shifted position and often split into multiple channels along the length of the stalactite.

The stalactite, packaged with dry ice, was shipped back to the U.S. Army Cold Regions Research and Engineering Laboratory for a quantitative analysis of its properties. From samples taken at $0.02 \mathrm{~m}$ intervals along the length of the core-ice, salinities were measured and horizontal thin sections were prepared. Measured ice salinities ranged from 7 to $10 \mathrm{ppt}$ but we believe that the actual in situ values were significantly higher, as a considerable amount of brine drainage occurred when the stalactite was retrieved. The thin sections were photographed under polarized light to identify the ice-crystal structure (Tucker and others, 1987). A personal computer-based image-processing system (Perovich and Hirai, 1988) was then used to determine the ice area, the brine-channel area and the relative amounts of frazil and columnar ice for each of the sections.

Figure 4a shows vertical profiles of the cross-sectional area of the brine channels and the ice. The cross-sectional area of the brine channels varies between 3 and $9 \mathrm{~cm}^{2}$ for the top $0.25 \mathrm{~m}$, then increases gradually with depth to values typically in the $7-15 \mathrm{~cm}^{2}$ range. The cross-sectional area of the ice averages $60 \mathrm{~cm}^{2}$, with fluctuations of $\pm 10 \mathrm{~cm}^{2}$ throughout the length of the stalactite. This indicates that, in the mature part of the stalactite, the outside diameter and the ice volume do not vary significantly with depth. Using the photographs taken between crossed polarizers, we determined the relative areas of frazil and columnar ice in each thin section. As Figure $4 \mathrm{~b}$ indicates, the sections were typically composed of $30 \%$ frazil and $70 \%$ columnar ice with fluctuations of $\pm 10 \%$. There was no significant variation in the relative amounts of frazil and columnar ice along the length of the stalactite.

The internal structure of the stalactite is illustrated in the horizontal thin-section photographs (Fig. 5). The four thin sections were located at (a) $0.22 \mathrm{~m}$, (b) $0.28 \mathrm{~m}$, (c) $0.30 \mathrm{~m}$ and (d) $0.46 \mathrm{~m}$ along the stalactite. The section at $0.22 \mathrm{~m}$ (Fig. 5a) shows the most basic structure observed and is representative of roughly half of the retrieved stalactite. It consists of a single, round brine channel near the center immediately surrounded by an inner zone of frazil ice and then by a ring of columnar ice. Usually, the collection of frazil ice was to one side of the brine channel. Figure $5 \mathrm{~b}$ and c illustrates how quickly the size and shape of the inner brine channel can change. Over a distance of 


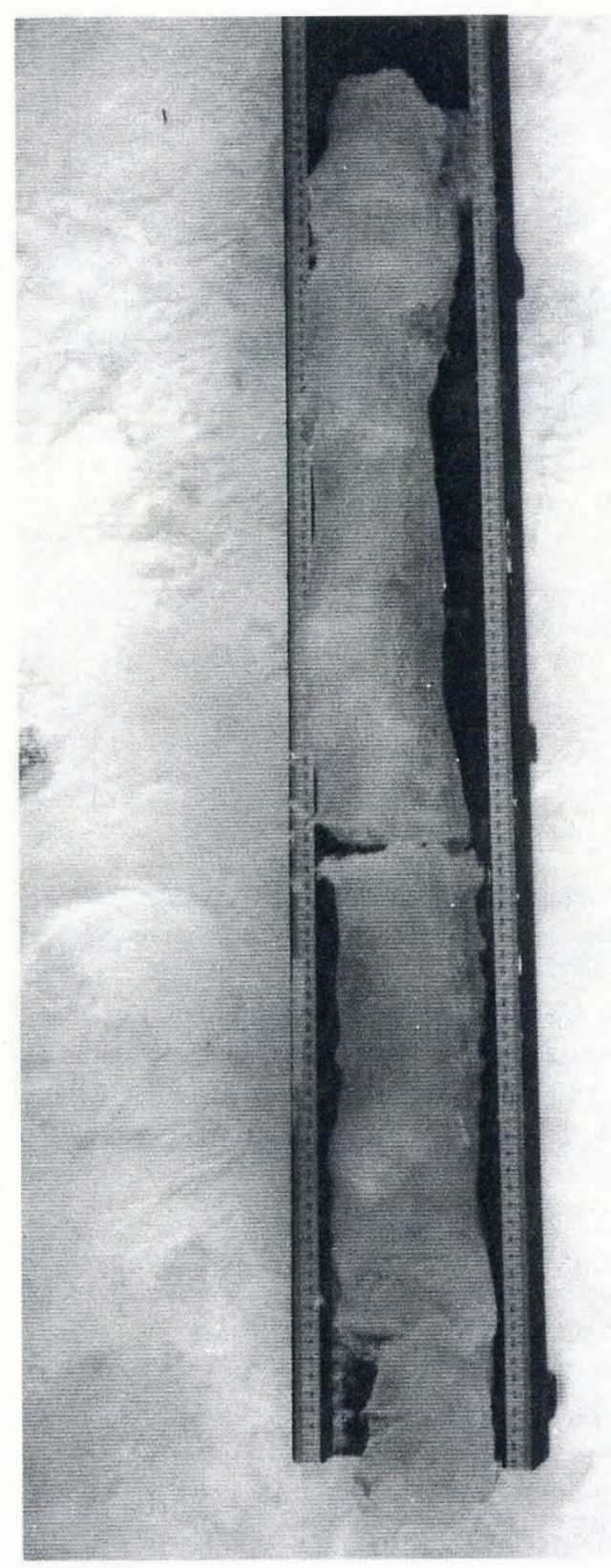

Fig. 3. Photograph of the ice stalactite taken immediately after retrieval. Though there are some bumps and curves in the stalactite, the outer diameter is fairly constant along its length.

only $0.02 \mathrm{~m}$, the size of the brine channel was reduced by a factor of 6 and the shape changed from a large triangle to a small circle. As Figure $5 \mathrm{~d}$ indicates, not only can the size and shape of the brine channel change but the number of channels can also vary. In this thin section, the brine channel had divided into five separate subchannels. The variability in the size, shape and number of brine channels, along with the presence of frazil-ice crystals, indicates that the fluid flow inside the stalactite was convectively unstable. This is consistent with Martin's (1974) suggestion that convective instabilities develop inside the stalactite, due to variations in the density of the brine, and cause overturning.

The columnar ice that forms the outside wall of the stalactite is nucleated from the frazil-ice crystals that form its core. Once initiated, the columnar crystals usually extend all the way to the outside wall of the stalactite. A crystal-fabric analysis of the thin sections showed that the growth of the columnar ice was directed radially outward, with the $c$ axes of the crystals lying in the horizontal plane perpendicular to the growth direction, which is the same relative crystal orientation as columnar ice found in a seaice sheet. For the stalactite, the heat flow is directed radially outward and for a sea-ice sheet it is directed upward.

\section{DISCUSSION}

As mentioned earlier, we believe that the subsequent brine drainage of rafted ice provided the source of brine needed to form the stalactite. For this to be true, there must have been a sufficient quantity of brine available in the young lead ice. No direct measurements were made of the volume of brine expelled from the stalactite. While a brine plume draining from the stalactite was observed in the ROV video, we were unable to measure the plume temperature, salinity or flow rate.

It is possible, however, to formulate rough estimates of the heat content of the stalactite and of the volume of rejected brine that served as the necessary heat sink. To first order, the heat content $(Q)$ of the stalactite is simply $Q=W L_{\mathrm{f}}$, where $W$ is the weight of the ice in the stalactite and $L_{\mathrm{f}}$ is the latent heat of fusion of ice $\left(0.33 \mathrm{MJ} \mathrm{kg}^{-1}\right)$. The weight of the retrieved part of the stalactite was $3.1 \mathrm{~kg}$. We can only estimate the weight of the part that was lost. In the video, it appeared to be about $0.75 \mathrm{~m}$ long and $0.08 \mathrm{~m}$ in diameter. The ice content is not known but from its lack of cohesiveness we shall assume that the lower part was $25 \%$ ice and $75 \%$ brine. This gives an ice weight for the lower part of approximately $0.9 \mathrm{~kg}$ and a total stalactite weight of $4.0 \mathrm{~kg}$. Thus, the heat content of the entire brine stalactite is roughly $1.35 \mathrm{MJ}$. The volume of rejected brine $(V)$ needed to extract the heat content of the stalactite is

$$
V=\frac{Q}{\beta \rho_{\mathrm{b}} c\left(T_{\mathrm{b}}-T_{0}\right)}
$$

where $\beta$ is the fraction of the heat extracted from the brine that goes to freezing the stalactite, $\rho_{\mathrm{b}}$ is the density of the rejected brine, $c$ is the specific heat of the brine

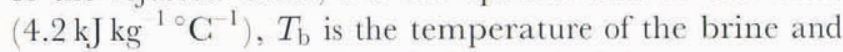
$T_{0}$ is the temperature of the underlying sea water $\left(T_{0} \sim-1.7^{\circ} \mathrm{C}\right)$. According to Martin's laboratory experiments, a minimum of half of the heat extracted by the cold brine contributes to the formation of the walls of the stalactite $(\beta=0.5)$. The remaining heat is lost to ice crystals that grow in the vicinity of the tip of the stalactite but are swept out to the underlying ocean. The density of the brine plume was determined from ice physicalproperty measurements, which showed that the lead ice had a bulk salinity of $18 \mathrm{ppt}$ and a mean temperature of $-10^{\circ} \mathrm{C}$. Assuming that the brine was at its salinitydetermined freezing point and had a temperature of $-10^{\circ} \mathrm{C}$, then the brine salinity was $150 \mathrm{ppt}$ (Fujino and others, 1974) and the density was $1120 \mathrm{~kg} \mathrm{~m}^{-3}$ (Gebhart and Mollendorf, 1977). Substituting these values into Equation (1) gives an estimate of 701 for the volume of brine that flowed through the stalactite. Based on these 

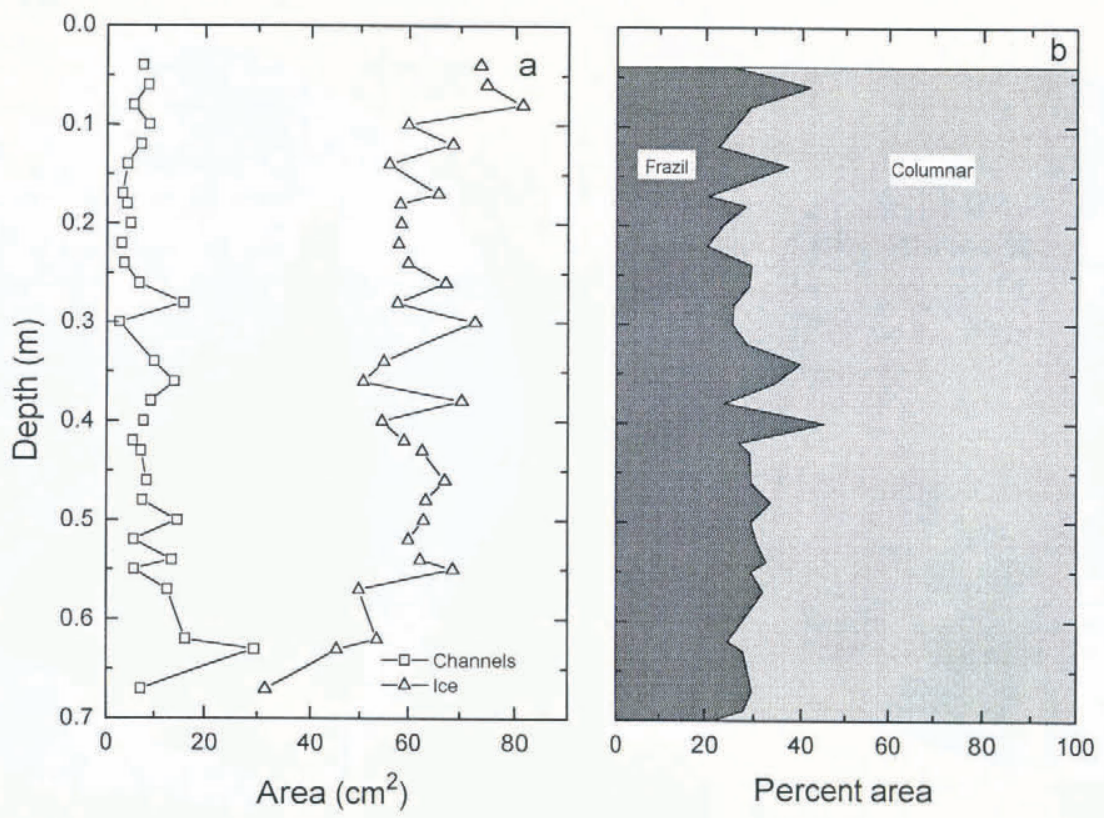

Fig. 4. Plots of (a) the cross-sectional area of ice and brine channels along the length of the stalactite and (b) the relative amounts of frazil and columnar ice in the stalactite. Zero depth corresponds to the base of the stalactite.

approximations, then, for a flow period of $15 \mathrm{~h}(0600$ $2100 \mathrm{~h}$ ), the average flow rate was $1.3 \mathrm{mls}^{-1}$. This is an order of magnitude less than the value of $18 \mathrm{mls}^{-1}$ estimated by Dayton and Martin (1971) for Antarctic stalactites.

Could the rafted ice supply 701 of brine to the stalactite? As described earlier, the underwater video indicated that the stalactites were spaced roughly $5-10 \mathrm{~m}$ apart and were located $1 \mathrm{~m}$ from the edge of the thick ice. We also observed that the strip of young lead ice that had rafted on to the thick ice along the length of the lead was $3.5 \mathrm{~m}$ wide and $0.04 \mathrm{~m}$ thick (Fig. 2). From this, we assumed a stalactite "drainage basin" that was $4.5 \mathrm{~m}$ wide, $5-10 \mathrm{~m}$ long and $0.04 \mathrm{~m}$ thick, for a total ice volume of $0.9-1.8 \mathrm{~m}^{3}$. Ice with a temperature of $-10^{\circ} \mathrm{C}$ and a salinity of $18 \mathrm{ppt}$ has a brine volume of $10 \%$ (Frankenstein and Gardner, 1967). Therefore, the total amount of brine in the "drainage basin" is 90-180 l, implying that $40-80 \%$ of this brine drained through the stalactite. While not definitive proof that the rafted ice was the brine source for the stalactite, it is certainly supporting evidence,

The likelihood that deformed ice was the brine source for the stalactite raises an intriguing question: what role does deformation play in the desalination of young lead ice and, consequently, the input of salt to the ocean? Conventional thinking regarding desalination has been directed towards an ice growth only scenario Morison and others, 1992). In the simplest case under these conditions, the salt flux due to brine rejected from undeformed ice is distributed uniformly in space, and the rate of rejection varies smoothly with time, reaching a maximum within the first few hours of growth, then decreasing as the ice-growth rate decreases. The observations described in this paper, however, suggest that deformation of the young ice may considerably complicate this picture and could cause the salt flux to be more variable, in both time and space.
While we do not have the detailed observations necessary to assess fully the impact of dynamics on ice desalination, we can gain some perspective on the role of deformation in the desalination process by comparing the amount of salt rejected during formation of the stalactite to that which occurred in an undeformed ice sheet. This is done by keeping in mind that there is considerable natural variability in the rate and mechanisms of ice desalination, and results from a comparison of two cases are by no means definitive. Data for the undeformed case come from measurements made a few days earlier at a different lead, where there was little deformation. Meteorological conditions at both lead sites were similar during the initial phase of ice growth: skies were clear, the wind was light and the average daily air temperature was $-21^{\circ} \mathrm{C}$. Ice cores were periodically removed from the growing lead ice and analyzed for temperature, salinity and structure. Following the methodology of Gow and others (1990), time-series measurements of bulk-ice salinity $\left(S_{\mathrm{b}}\right)$ and ice thickness $(H)$ can be used to estimate the desalination rate and the amount of salt rejected per unit area $\left(S_{\mathrm{r}}\right)$ from the ice to the ocean. The desalination rate is simply the change in the bulk salinity of the ice per unit time $\left(\mathrm{d} S_{\mathrm{b}} / \mathrm{d} t\right)$. The amount of salt rejected is defined by

$$
S_{\mathrm{r}}=\rho H\left(S_{\mathrm{w}}-S_{\mathrm{b}}\right) / 1000
$$

where $\rho$ is the density of the sea ice $\left(920 \mathrm{~kg} \mathrm{~m}^{-3}\right)$ and $S_{\mathrm{w}}$ is the salinity of the water $(30 \mathrm{ppt})$. We can then determine the salt flux $\left(S_{\mathrm{f}}\right)$ by taking the time derivative of the salt rejected $\left(S_{\mathrm{f}}=\mathrm{d} S_{\mathrm{r}} / \mathrm{d} t\right)$. In order to make this calculation for the deformed ice, we recall our earlier estimates that approximately $40-80 \%$ of the brine in the rafted ice drained through the stalactite, and realize that additional brine may have drained from the rafted ice but not through the stalactite. Based on this, we will assume a conservative estimate of $60 \%$ total brine loss over the 

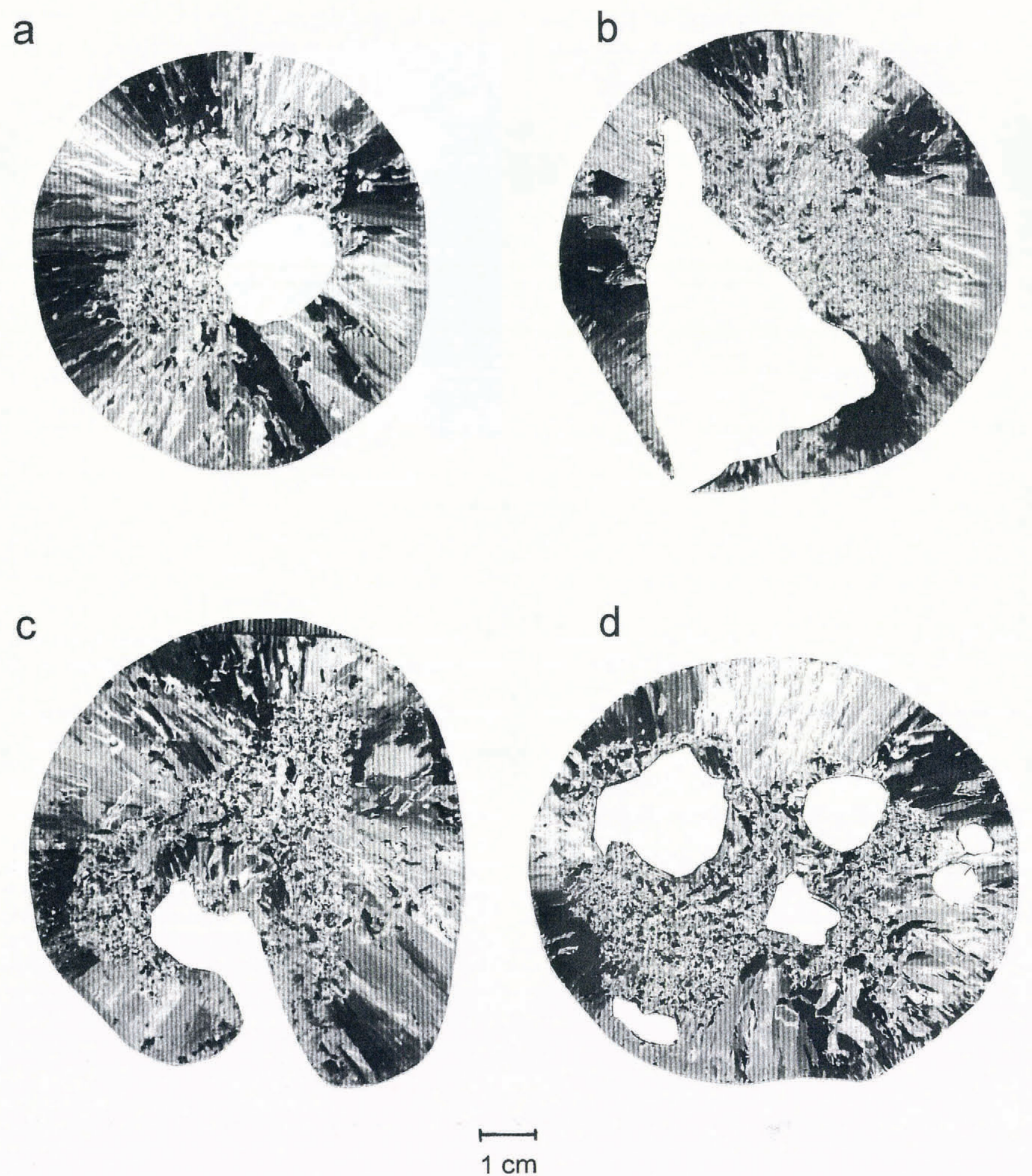

Fig. 5. Photographs, taken under crossed polarizers, of thin sections from depths of (a) $0.22 \mathrm{~m},(\mathrm{~b}) 0.28 \mathrm{~m},(\mathrm{c}) 0.30 \mathrm{~m}$ and (d) $0.46 \mathrm{~m}$

described "drainage basin", in effect reducing the bulk salinity of the rafted ice from 18 to $7 \mathrm{ppt}$ over a $15 \mathrm{~h}$ period.

Table 1 summarizes ice thickness, bulk salinity, icedesalination rate, the total salt rejected and the salt flux from the ice for the deformed and undeformed cases. As expected, the desalination rate in the undeformed ice reached a maximum during the first few hours, when growth rates were large, and then decreased as the rate of growth slowed. In the deformed ice, even using the conservative estimate of brine loss, there was a high desalination rate of $17.6 \mathrm{pptd^{-1 }}$. This value was the average desalination rate for the entire period we observed the stalactite. In all likelihood, the rate was higher when the ice first rafted, then decreased with time. Aside from the initial few hours of growth, when the rates were comparable, desalination was always greater in the deformed ice than in the undeformed. This illustrates that lifting highly saline ice out of the water is an effective desalination mechanism. 
Table 1. A comparison belween undeformed and deformed ice of desalination and salt flux from the ice to the ocean. Time denotes how long the lead ice has been growing

Time Thickness

Bulk salinity

Desalination rate

$\mathrm{h}$

$\mathrm{m}$

ppt

$\Delta \mathrm{ppt} \mathrm{d}^{1}$

\section{Deformed}

14

29

\section{Undeformed}

0

0

56.2

While the deformed ice has a higher desalination rate, the salt flux from the deformed ice is, for the most part, smaller than from the undeformed. The larger flux in the undeformed case results from the contribution to the salt flux made by the brine rejected from the new ice growth. In the deformed ice, growth stopped once it rafted. Though not as large as the initial growth stage of the undeformed ice, the salt flux resulting from deformation was still a considerable $0.7 \mathrm{~kg} \mathrm{~m}^{-2} \mathrm{~d}^{-1}$. Similar estimates of the salt flux from ice growing in a freezing lead made by Gow and others (1990) indicate that, after $7 \mathrm{~d}$ of growth, the salt flux decreased to an average of $0.17 \mathrm{~kg} \mathrm{~m}^{2} \mathrm{~d}^{-1}$. More important to consider are differences in the character of the salt flux. In the undeformed case, the salts are rejected uniformly over a wider area. The deformed case exhibits much more spatial variability, with the brine injected through the stalactite into the ocean as a highly concentrated point source.

To determine the impact of this plume of cold, dense brine on the thermohaline structure of the underlying water, the question of its penetration depth must be addressed. The penetration depth is a function of the density of the brine plume relative to the underlying sea water, as well as the rate and character of the injected brine. In the case we observed, the brine plume exiting the stalactite had a higher density than the underlying sea water: $1120 \mathrm{~kg} \mathrm{~m}^{-3}$ compared with $1020 \mathrm{~kg} \mathrm{~m}^{-3}$. The stalactite plume, as seen in the video, appears to become nearly horizontal within $1 \mathrm{~m}$ of the stalactite. Since the ambient horizontal flow was an order of magnitude greater than the estimated vertical velocity of the brine in the stalactite, it is likely that the plume would have been carried several hundred meters downstream before it settled to the base of the mixed layer at a depth of $30 \mathrm{~m}$. Rough estimates determined using smoke-stack theory (Csanady, 1965; Slawson and Csanady, 1967) indicate that over this distance the plume would have spread to a few meters across, causing a marked decrease in the salinity perturbation. This suggests that, while the stalactite plumes may be identifiable some distance from the source and could contribute to mixing in the upper layer, it is unlikely that they would penetrate the pycnocline. These comments are speculative but they do suggest that more detailed modeling aimed as assessing the impact of the brine plume on the thermohaline structure of the upper ocean is warranted.

This study has provided information on the formation and morphology of under-ice stalactites and has indicated that ice deformation may make an important contribution to the process of ice desalination. It has also raised questions that need to be addressed in future studies. These range in scope from the formation process of the stalactite to the oceanographic implications of deformationally driven brine drainage. For instance, in the case of stalactite formation, it was shown that the rafted ice had enough brine available to form the stalactite, if there was significant horizontal movement of the brine within the rafted sea-ice sheet. A thorough structural analysis of the deformed ice, directed towards identifying the network of brine drainage features, should be made to confirm this hypothesis. Another related question concerns the reason why the brine exits at regularly spaced, discrete points rather than continuously, along the line formed by the junction of the tilted, rafted ice and the level undeformed lead ice. One possible explanation is that there were small-amplitude undulations in the rafted ice that ran along the edge of the lead. The combination of these undulations with the junction of the rafted and undeformed ice (Fig. 2) would effectively create a drainage basin for each of the stalactites. Elevation measurements to define the small-scale topography of the sea-ice sheet surrounding a stalactite would be useful in evaluating this hypothesis.

The role of deformation in the desalination of young ice is of potential oceanographic importance. Though limited, our observations during both the LeadEx pilot and main experiments indicate that the deformation of thin lead ice was pervasive and that rafting was common. It is important, therefore, to determine and quantify the relative contribution of deformation in the process of desalination of sea-ice sheets so that the entire process, including both the deformed and undeformed components, can be appropriately represented in models. The formation of the stalactites due to rafting of thin ice over thick ice probably represents an extreme case of enhanced desalination due to deformation. It does serve to show, however, that deformation can have an impact on both the quantity and nature of brine drainage from a sea-ice sheet. Other common cases that need to be considered include the rafting of thin ice over thin ice and the building of ridges and rubble. The impact of deformation on desalination in these instances may be different than the case of thin-ice rafting over thick ice. For example, when thin ice rafts over thin ice, there is little change in 
freeboard compared to the instance when thin ice rafts over thick ice. Without this change in freeboard, there is little increase in the elevation of the sea-ice sheet and subsequently little enhanced drainage. In this case, deformation also increases the total ice thickness, thereby reducing the salt flux due to new growth. Another characteristic that is likely to influence the amount of brine drainage from deformed ice is the original thickness of the sea-ice sheet. Though the bulk salinity of a sea-ice sheet typically decreases with increasing thickness, thicker ice may have more total brine available for drainage than thinner ice. However, it does not necessarily follow that more brine will drain from thicker sea-ice sheets during a deformation event, since the thicker ice is colder and may lose a smaller fraction of its brine. Additional field and laboratory measurements of the temporal changes that occur in the salinity profile of the ice before and after deformation, coupled with measurements of the physical properties of the ice and detailed observations of the nature of the deformation, are necessary before these processes can be accurately described. Key issues that need to be investigated include determining the fraction of the brine that is lost from deformed ice and how this fraction varies with thickness and time. Such results then need to be coupled with large-scale studies of the extent and frequency of the various modes of deformation in order to assess the oceanographic impact of desalination due to deformation.

\section{SUMMARY}

Large ice stalactites, $1-2 \mathrm{~m}$ in length and $0.05-0.10 \mathrm{~m}$ wide, were observed under a deformed lead in the Beaufort Sea. These stalactites grew rapidly around plumes of cold, dense brine. The source of the brine was enhanced drainage that resulted when salty lead ice rafted on to adjacent thick ice. A morphological analysis of a retrieved stalactite indicated that the brine flowed through a tortuous central channel of variable size that often branched into several sub-channels. The stalactite was composed of a combination of frazil $(30 \%)$ and columnar $(70 \%)$ ice, typically with an inner zone of frazil ice adjacent to the brine channel, surrounded by a ring of columnar ice. The columnar ice grew radially outward with the crystal $c$ axes in the horizontal plane, perpendicular to the growth direction. Estimates of the heat and brine associated with stalactite formation determined an average brine-flow rate of approximately $1 \mathrm{ml} \mathrm{s}^{-1}$ through the stalactite. Further calculations show that there was indeed an ample supply of cold, dense brine available in the rafted lead ice to provide this flow and form the stalactites. The brine drained through these stalactites represents a significant part of the brine lost from deformed young ice to the ocean. Since thin, warm, lead ice is easily and frequently deformed, it follows that the dynamics of the lead ice, as well as the thermodynamics, may have an effect on the thermohaline structure of the upper ocean.

\section{ACKNOWLEDGEMENTS}

The authors thank the U.S. Office of Naval Research for funding this work under the Leads Initiative. They also thank S.F. Ackley, A.J. Gow and three anonymous reviewers for their insightful and helpful comments.

\section{REFERENCES}

Csanady, G. T. 1965. The buoyant motion within a hot gas plume in a horizontal wind. J. Fluid Mech., 22, Part 2, 225-239.

Davton, P. K. and S. Martin. 1971. Observations of ice stalactites in McMurdo Sound, Antarctica. J. Geophys. Res., 76 6), 1595-1599.

Frankenstein, G.E. and R. Gardner. 1967. Equations for determining the brine volume of sea ice from $-0.5^{\circ} \mathrm{C}$ to $-22.9^{\circ} \mathrm{C}$. J. Glaciol., $6(48)$, $943-944$.

Fujino, K., E. L. Lewis and R. G. Perkin. 1974. The freezing point of seawater at pressures up to 100 bars, f. Geophys. Res., 79 12), 1792 1797.

Gebhart, B. and J. C. Mollendorf. 1977. A new density relation for pure and saline water. Deep-Sea Res., 24, 831-848.

Gow, A.J., D. A. Meese, D. K. Perovich and W. B. Tucker, III. 1990. The anatomy of a freezing lead. f. Geophys. Res., 95 C10), 18,22118,232 .

Kaufman, D. W. 1960. Sodium chloride. New York, Reinhold.

Kozo, T. L. 1983. Initial model results for Arctic mixed layer circulation under a refreezing lead. J. Geophys. Res., 88 C.5), $2926-2934$.

LeadEx Group. 1993. The LeadEx Experiment. EOS, 74 (35), 393, 396 397.

Martin, S. 1974. Ice stalactites: comparison of a laminar flow theory with experiment. 7. Fluid Mech., 63, Part 1, 51-79.

Morison, J.H., M. G. McPhee, T. B. Curtin and C. A. Paulson. 1992. The oceanography of winter leads. J. Geophys. Res., 97 C7), 11,199 11,218 .

Paige, R. A. 1970. Stalactite growth beneath sea ice. Science, 167, 171-172.

Perovich, D. K. and A. Hirai. 1988. Microcomputer-based imageprocessing systems. J. Glaciol., 34(117), $249-252$.

Slawson, P. R. and G. T. Csanady. 1967. On the mean path of buoyant, bent-chimney plumes. J. Fluid Mech., 28, Part 2, 311-322.

Smith, D. C.. IV and J. H. Morison. 1993. A numerical study of haline convection beneath leads in sea ice. J. Geophys. Res., 98 C6), 10,069 $10,083$.

Tucker, W.B., III, A.J. Gow and W.F. Weeks. 1987. Physical properties of summer sea ice in the Fram Strait. f. Geophys. Res., 92 (C7), 6787-6803.

Weeks, W.F, and S.F. Ackley. 1986. The growth, structure, and properties of sea ice. In Untersteiner, N., ed. The geophysics of sea ice. New York, Plenum Press, 9-164. 